\title{
Exploring the characteristics, attitudes to targeting and relationship marketing of small ethnic minority businesses
}

Received (in revised form): 12th August, 2003

\section{Len Tiu Wright}

is a research professor at Leicester Business School, De Montfort University, Leicester. She is on the editorial boards of a number of leading marketing journals and has written for small and medium-sized enterprise and technology publications. The majority of her research interests and publications are in the international marketing, marketing research and e-marketing fields. She is the Founding Editor of Qualitative Market Research - An International Journal.

\section{Lynn M. Martin}

is Senior Academic for Innovation and Entrepreneurship at UCE Business School in Birmingham, UK, and Director of EU Asia programmes and the doctoral business programmes. She holds a doctorate and is the author of many papers, commissioned reports and book chapters on knowledge, innovation and the impact of new technology in small firms. She is a consultant in knowledge management and innovation in large and small organisations. In addition to her programmes with China and India, her international work includes expert reports for NATO regeneration actions and EU and INTAS reviews of research.

\section{Merlin Stone}

is a professor at Bristol Business School, Business Research Leader with IBM and a director of QCi Ltd and The Database Group Ltd. He is the author of many papers and more than 20 books on marketing and customer service. He has consulted to companies in many sectors on CRM and customer service. He is a founder fellow of the Institute of Direct Marketing, a fellow of the Chartered Institute of Marketing and on the editorial advisory boards of many journals.

\section{Len Tiu Wright}

Leicester Business School, De Montfort University, Bede Island, The Gateway, Leicester LE1 9BH, UK.

Tel: +44 (0)116 250 6096; Fax: +44 (0)116 2506329 ; e-mail: Iwright@dmu.ac.uk

\begin{abstract}
This paper presents a discussion of the literature and research about small ethnic minority businesses (SEMBs). Their business practices and characteristics, family and community ties and attitudes concerning measuring, targeting and relationship marketing are explored. Conclusions are drawn about ethnic businesses and recommendations for further study are given.
\end{abstract}

\section{INTRODUCTION}

This paper looks at the issues faced by small ethnic minority businesses (SEMBs), their entrepreneurship orientations, their efforts at nurturing and managing relationships in building their businesses and their attitudes to targeting their products and services. Findings from qualitative research with a sample of SEMBs are presented. The research aims to identify key needs within such SEMBs to provide useful support for further research while extending the existing literature about entrepreneurial experiences in business and relationship marketing to target their local communities.

SEMBs are becoming an increasingly important area as more of such businesses emerge in the West. ${ }^{1}$ For instance, there has been some examination of purchasing patterns by different ethnic groups, notably in the USA. ${ }^{2}$ There are other features, for instance, where the results 
and processes surrounding the targeting of ethnic groups have received surprisingly little attention, eg via advertising in direct marketing programmes or the exploration of possible differences between assimilated and less assimilated groups. ${ }^{3}$

\section{CHARACTERISTICS OF SEMBS}

Small firms, which account for the large majority of enterprises, are present in most industries and are as diverse in their operations as they are disparate in their internal cultures. Small ethnic minority businesses (SEMBs) are diverse and disparate in their nature.

Characteristically, small ethnic minority businesses are managed by single or married proprietors, or are family-owned enterprises, set up to exploit a niche in their local markets and to serve their local communities. For decades, owner-managers have displayed 'the need to attain and preserve independence' at the risk of 'conflict even with the interests of their own business', but where they provide 'a wide range of choice ... personal service ... and a willingness to contribute experience to the service of the community' where they live. ${ }^{4}$

What they do not have are the advantages that large companies possess: economies of scale in production; resources to invest in technologies to implement e-customer relationship management (e-CRM); and large customer databases with computerised technologies to pinpoint with accuracy the possible combinations in their targeted segments. Typically, SEMBs do not have at their disposal, the variety of quantitative data and measures to determine market attractiveness, eg size and share of market, rates of growth, use of technology, trends in buying behaviour, extent of competition and assessments of marketing environment conditions. The emergence of powerful user-friendly databases have enabled large organisations to build a degree of intimacy with their customers, ${ }^{5}$ thus igniting interest in relationship marketing within Western economies. ${ }^{6}$ SEMBs, however, are using social ties to bind their relationships with their customers in other ways. Using social aspects of exchange to form part of the total exchange benefits received by customers, attempts by external suppliers to attract the same customers on the basis of more tangible economic benefits, may fail. This can, in part, explain why some ethnic businesses are successful at establishing themselves by establishing such a form of relationship marketing within their communities to provide the quality and depth of personal service to their customers.

Conversely, as ethnic businesses have found and as indicated in the research findings of this paper, these factors can make it more difficult for SEMBs to obtain credit or financial backing. Western financial institutions that are seeking to concentrate on their more lucrative customer accounts view small businesses, particularly those from ethnic minorities, as high-risk ventures. There are also complex issues that arise due to the interplay between market forces, internal organisational dimensions and changes in ownership circumstances. There are large gaps in diversity of size and resources between SEMBs and large organisations. So it is common to find that SEMB owner-managers apply limited financial rather than statistical measures and fall back onto relationship building within their ethnic communities to solve marketing problems.

\section{CONTRIBUTION OF RELATIONSHIP MARKETING}

Relationship exchanges have operated as a norm from ancient times and in different cultures. ${ }^{7}$ The problems of 
nurturing and keeping customers in competitive markets have, however, long been a preoccupation of many business. ${ }^{8}$ The key issue of relationship building, whether internet-based business-toconsumer or through nurturing personal relationships is of importance to businesses in general. The internet has contributed to the growth of large ethnic businesses whose entrepreneurs have taken advantage of both forms of relationship marketing to spawn new networks and to establish new markets further afield, eg exporting Caribbean hair products and ethnic foods from their adoptive European countries to their countries of origin and to ethnic communities elsewhere in the West.

Within local markets, relationship marketing strategies are not appropriate to all buyer-seller relationships. Sellers of generic commodity products may find relationships difficult to achieve in a market where customers have no reason to remain loyal to one supplier and routinely seek out the supplier which offers the lowest prices or is the most accessible. ${ }^{9}$ An advantage SEMBs have, rooted as they are in their local ethnic communities, is their ability to know the indigenous mix of customers through the development of close ties and relationships near to home. This has helped them to survive despite competitive market conditions at home and abroad which have resulted in good products and services alone being inadequate, at times, for an SEMB to gain local competitive advantage. So relationship marketing needs to reflect the value system of the specific population to which it is targeted. ${ }^{10}$

There is, unfortunately, no clear, unified paradigm because the varying interpretations of what constitutes 'relationship marketing' and what it appears to be to different people, mean that there are many different definitions of relationship marketing. ${ }^{11}$ Given the lack of consensus as to what it is there are related gaps in knowledge in how to develop effective programmes of relationship marketing. ${ }^{12}$ What is known from the literature is that where there is a myriad of types of transactions by individuals and, where short-term discrete transactions occur, it is customer attention rather than retention which is the focus for targeting customers. ${ }^{13}$ Where long-term, ongoing transactions occur the building of new relationships would need time to mature. There is, however, a need for all businesses to see relationship marketing in the longer-term context and to deliver a fundamental need to deliver a quality and depth of relationship that customers value. ${ }^{14}$

The influences upon and barriers to relationships between SEMBs and their customers are affected by the circumstances and length of time in which their relational exchanges take place. The ongoing nature of utilising existing community links and drawing from local talent add to the complexity in studying SEMBs. So the qualitative study in this paper attempts to contribute to closing a gap in knowledge by exploring how SEMBs develop their own forms of relationship marketing in building their businesses.

\section{ISSUES AND OPPORTUNITIES}

As might be anticipated, first generation immigrants necessarily identify the need to satisfy key basic needs, to find employment, ensure stability and security rather than looking for satisfaction or other self-actualisation. The next generations, however, have grown up in more secure conditions, with more education and greater opportunities to enter different kinds of businesses, with the extra advantage of links to their parental country of origin. This evolution 
of new approaches by second and third generations is evidenced in a number of ways, fundamental to the way attitudes have formed and relating directly to how business is done. Differences in food consumption for instance, by first and second generation Pakistani family members in Bradford, typify the duality and potential for conflict in other areas of their lives. ${ }^{15}$

First generation immigrants move in home and work environments providing room for their customs and values, underpinned by religious beliefs.

Integration and relationship building with the wider host population was frequently limited to 'bonding ties'. These ties link the individual with the immediate and wider family network together with the community network. Elders in both the family and the wider community were seen as figures of both knowledge and authority, with children drawing on these ideas as they grew up, often in a mainstream educational culture. The duality experienced in several cultures may lead to continued isolation from mainstream cultures or to syntheses with the host community. ${ }^{16}$ This pattern emerges in different host countries and for different ethnic groups as seen in studies in the USA, ${ }^{17}$ Australia $^{18}$ and Belgium. ${ }^{19}$ Over time, immigrant groups often develop a synthesis of elements of their traditional culture and from the host culture. While an older generation cling to the memories and cultures of their homeland, their children and grandchildren adopt very different habits and styles. ${ }^{20}$ Targeting individual or business customers within ethnic minorities requires awareness of such a process and appreciation of the variations within a given ethnic group. Here ethnic businesses may have an advantage since non-ethnic business approaches may result in insensitivity and patronising communications. ${ }^{21}$
In ethnic family firms, the problematic nature of succession in the UK is emphasised by earlier researchers. ${ }^{22,23}$ Here family firms no longer attract younger family members with professional ambitions who look for higher status and greater monetary rewards than their family businesses could provide. Additionally, working conditions seen as inevitable by first generation family members, are seen by their potential successors as unsupportable given the long working hours, low rates of returns and unattractive environments. Firms may be sold at this stage to provide resources for the parents' old age. In other cases, however, the sale of assets or whole firms may be used as capital to start a new enterprise or to develop an existing business. ${ }^{24}$ Although, in the research study, the original companies were low technology, based in the clothing and retail sectors, the new firms are high technology and are seen as wealth creating or as members of the new knowledge economy.

Proactive responses to problematic business succession can involve disruptive innovation, including the use of funds from the sale of low technology firms to fund the set up or development of high technology firms. Where new technology is brought into existing firms there may be initial problems despite greater long-term potential since existing customers may not perceive any value in these changes. This response has a higher potential risk than the other responses since it involves possible changes to the established customer base. The key may lie in clear understanding of customer needs and of how to attain new customers while retaining existing customers. This is surely the key to effective customer relationship marketing, whatever the technology employed to support this.

The development of new SEMBs 
demonstrates change over time. As anticipated by commentators on social capital, the younger generation is more integrated with the wider population. Members of this generation therefore have very different experiences and aspirations from their parents, often having professional status and higher educational qualifications. They may take roles within larger organisations or they may enter self-employment. They are, therefore, a focus for this paper. Further studies are needed to look at how such firms are funded and to track how this affects local communities, given the importance of local firms to the inner city areas. ${ }^{25}$

\section{METHODOLOGY}

SEMB respondents were identified by business support services and by other means, such as their membership of business associations. Initial interviews were held with those in business support agencies and ethnic business associations to define useful questions and to identify ethnic minority businesses to participate. A small sample of a dozen SEMBs was identified by this route. Apart from one property letting business that had been established for longer, the SEMBs were in the service sector, either as high technology firms or as professional service firms, and had been in operation for more than four years.

In the marketing research industry focus group discussions and in-depth interviews on a one-to-one basis are widely used. In-depth interviews are appropriate for small samples where more time can be spent in exploring the attitudes, motives and aspirations of ethnic minority entrepreneurs. In-depth interviews are also appropriate for use in questioning the support agencies and associations that are directly relevant in helping to set up services for ethnic minorities and directing them to sources of funds or to help further afield. The advantage of using unstructured interviews based upon a topical checklist is that they allowed the authors to examine what resources the SEMBs, support agencies and associations had available. Questions were allowed to be open-ended, enabling respondents to reveal their true motives and feelings and to add further information. To maintain consistency one interviewer carried out all the interviews. The information was transcribed, analysed qualitatively and recorded. The sequence of questioning was flexible and dependent on the respondents' answers, which enabled the direct use of quotes from respondents themselves, as presented in the 'Findings' of this paper.

Given that the research was of an exploratory nature it was inappropriate to use random sampling and quantitative measures. This was due to differences in types of businesses, the ethnic entrepreneurs' managerial stages of development, rates of growth and differing perceptions concerning expectations of the growth of their firms given the age factor of the owner/entrepreneur and family members' involvement. Moreover, compared to other methods, personal in-depth interviews had the advantage over postal and telephone surveys in that sensitivity in one-to-one discussions could elicit information from respondents which they would otherwise not have been prepared to give. Such respondents are reluctant to write down key qualitative statements on postal questionnaires or in verbal answers to cold calls on the telephone. The introduction of call centres and the increase in junk mail have added to the annoyances faced by recipients. Asking questions of SEMBs could be seen as prying so it was important to establish trust and consent from the respondents. 
To gain effective rapport with respondents face-to-face meetings were preferable to anything else.

\section{FINDINGS}

\section{Importance of succession and start-up}

Findings from the business support agencies and also by other researchers ${ }^{26}$ of family-owned businesses had identified key issues in the geographical areas relating to ethnic minority businesses. The successful second generation entrepreneurs in one area were investing in property rather than any other business or social opportunity. Purchasing land and property was seen as a secure thing to do and hence the businesses themselves were sometimes undercapitalised. In another area, there was a gradual movement of economic activity elsewhere, as first and second generation owners exited their businesses and the next generation chose to do something else. Conflicts within the family were reported by all those supporting ethnic businesses. This may, however, be true for many family firms since other studies have identified conflict in family firms at the succession stage.

In each case, the owners had developed their companies based on their own aspirations rather than their families'. The family had wanted them to go into specific career paths and/or to take over the family firm. Conflicts had arisen round their choice of study, then their need to be independent after that. The third generation had learned their lesson from their own parents but had not enjoyed an easy path.

'My father had ideas about his own life which he set aside to take over the firm from my grandfather. He couldn't see why I shouldn't do the same thing ... We had endless rows about it but in the end he accepted it.' (Male owner, media company)

'My mother has a degree and is very clever but she's never really been happy at work because she just helps with my grandfather's business. Helping out means a lot of things but it doesn't mean being valued, having high status or even being paid a decent wage. And of course she'll never run the company that will be inherited by her brother.' (Female owner, computer services company)

Conflicts, though, were often resolved amicably. In three cases, the new business had been started up on the same site as the family firm, to give the business stability and allow it rent-free access, to office facilities and support.

'They were very worried about me doing this when there was a nice secure job in a pharmacy all set up for me! At the end of the day that didn't matter because they are ready to help whenever they can.' (Male IT services company)

In four of the firms, initial finance had come from the sale of the family business. The retiring owners had returned to Asia or had purchased property in the surrounding countryside. This ensured that the need to borrow money was reduced, although the businesses being sold rarely had the monetary value ascribed to them by their owners. This over-estimation of the worth of a business at exit appears to be common. Business support services were also seen as 'quite useful' in providing new advice although advice was 'something an Asian never lacks everyone in your family has this for you, then there are the other older members of the wider community!'

Government initiatives were less well thought of.

'The initiatives for business are more effective than the ones they run just for 
Asian companies ... I try to avoid these schemes and projects because of the paperwork but also because I hate to be pigeonholed.' (Female, IT services).

'They have a picture of an Asian business as low skilled, first generation sweat shop ... of us as needy etc, whereas actually this company is built on high skills, solid education and accumulated business expertise - not just mine but also my father's and grandfather's.' (Male, IT services)

\section{Networking, forming and managing relationships in marketing}

Over a few generations, the use of bridging capital can gradually replace bonding ties within racial and ethnicity contexts as immigrants become more integrated into their host society. Hence, perhaps, the more bridging capital one has cultivated the fewer bonding types of capital one would have. ${ }^{27}$ Ethnic minority groups may, however, face barriers to entry into mainstream organisational and institutional structures of the host society, and so ethnic bonding ties may be more persistent. Nevertheless, once immigrants and their descendants are structurally assimilated, bonding ties will weaken. Assimilation may not, however, end ethnic identity and bonding ties as both network types have been found to coexist, eg the Japanese-American community.

The importance of social ties in the development of business relationships has been seen in earlier studies. Research with Chinese-Canadian consumers demonstrated that 'intracultural differences in consumer behaviour are inadequately explained by the psychological construct of ethnic identification, and that additional explanatory power is achieved when incorporating the ethnic homogeneity of social ties. ${ }^{28}$ The ethnic homogeneity of social ties exerts significant influence over an individual's consumption of ethnic products. This made it a much more robust predictor variable than ethnic identification. Having cross links between and within ethnic groups is, however, an important criterion in business performance. Ethnic businesses have made progress, as with the gaining of business awards or in achieving wide recognition for their work in communities, eg in developing multicultural marketing campaigns in Australia. ${ }^{29}$

In this study networking was seen as important by all the entrepreneurs, both formally and informally, while the wider family itself constituted a network supporting the firm.

'When I needed to find a graduate to work in the firm to help with the programming side, it was no problem, the word got round the family and a cousin from Scotland whom I'd never met emerged as the best person. Who needs recruitment agencies?' (Female, computer services company)

In the property letting business the landlord was successful in having full tenancy rates and long-staying tenants and attributed his success to relationship marketing.

'My criteria for letting are to make sure that in each of my ten houses I get the right group of tenants, ie each has to be a graduate, non-smoking, in a professional occupation and within the age range of early twenties to thirties. The relationships are based upon respect and informality. I don't have contracts or take deposits. In return my tenants pay their rents at the beginning of each month by direct debit. It is important to maintain a sense of humour, avoid disagreements or take sides. When there are maintenance jobs to do in the houses they are done promptly. I look after my tenants as good customers. Customer care and service are important.' (Male, property lettings) 


\section{A double-edged sword}

The SEMBs had few business models locally, but their owner-managers compared themselves to successful mainstream entrepreneurs. Richard Branson was seen as a key influence in terms of how he had started up doing something he enjoyed (a record business) then grown that to develop his enterprises. Ethnic business forums and associations were seen as very helpful in getting people together and making wider contacts, although some commented on the 'ghettoisation' which might ensue.

'You have to make sure you belong to mainstream associations too, otherwise you operate in an Asian world in Britain ... there are good business opportunities that you can miss if you don't open yourself up to the wider markets.' (Male, media company)

'My cousin has a printing business, my other cousin runs an advertising company. We have to use them because it wouldn't be appreciated to go outside the family. Sometimes they are very good but it's not like testing the market to see what new ideas come out and selecting a supplier based on their qualities alone ... if they let you down then you're still going to use them and they know that really.' (Male, IT services)

\section{How do these firms target their services?}

Marketing plans were in existence in six of the companies, with clear targets identified in each. The use of these plans was limited however, and related to the need to supply such documents to obtain bank loans or government funding. This pattern is not solely found in ethnic minority firms. In the four firms without a formal plan, marketing was described in terms of advertising and word-of-mouth to gain sales. New business was seen as key to survival, growing existing business was not always seen as a benefit due to the need to offer suitable rates for friends or family who had been in the first tranche of customers. These clients expected a good deal from the firm and the owner for relatively little in monetary terms but their connection to the owners and the need to build reputation in the community meant that this had to be ignored as a negative factor.

Targeting was not often well defined either, for existing or new customers, and heavy reliance was placed on organic generation of leads. Word-of-mouth was a key feature. Despite the view above about the value of non-EMB networking, business often came from British Asian sources. In six of the firms, over half the business was from other Asian companies or from individual British Asian customers. Advertising and mailshots had brought in a more diverse customer group but word-of-mouth tended to be based on family, Asian community or Asian business connections. In the other four firms this was not so evident, possibly due to the nature of their business or the way in which it was perceived by others.

'Trust is something people need to have in you if they're going to interact with you, if it's remote purchase then it's not such a big deal, as they're looking at the product as something to trust, you being Asian doesn't come into it.' (Male, IT services)

'People need to feel that they can trust you, and I think sometimes they might be uncomfortable with an Asian in certain roles, but accountancy and the law are both alright. We can do those and be respected because there are still these stereotypes.' (Male, IT services)

'How many Asian footballers are there in the premier league? You can say what you like but we still have a particular image and unless people have come in contact with 
Asians on a regular basis they still feel very suspicious of us doing certain jobs, or roles.' (Male, law firm)

'I don't network much in the Asian business associations because it's dominated by older men who still have very fixed ideas about what a little woman like me should be doing. When I meet other (non EMB) business owners it's a perk to be an Asian women because they're intrigued by it. There aren't many of us attending mainstream business associations so they come and talk to me. I can easily network although this doesn't always lead to new business outside of the community.' (Female, IT services)

There are assumptions among business support agency representatives that ethnic businesses will succeed by marketing and targeting more widely ethnic minority members. The option to do so may be tempting, however there is a need to recognise the complexity of targeting, avoid stereotypical assumptions and respect variations within the usual ethnic definitions. Using the term 'Asian' does not reflect a person's origins, language, religion or culture hence targeting large groups purely on the basis of ethnicity may be unwise. Relying on geographical concentration, language differences, religion or dress to make distinctions between minorities may be unwise since residing in a particular district, speaking a certain language and professing a particular faith, does not automatically result in shared preferences and outlook. Furthermore, there are ethical problems with using ethnic origin data as a targeting variable or when direct mail is the medium.

\section{Measuring results}

The measurement of outcomes in terms of leads generated against time invested or other means was not a feature of any of these companies. The sentiment was expressed that there was not enough time to measure anything, dealing with the here and now was enough.

Measuring percentage progress of income however was part of the monthly process in most firms. While this represented an indicator of how solvent the firm was and showed a pattern of seasonal ups and downs over a 12-month period, it was less useful as an aid to planning or to developing a strategy to take the business forward. It was also seen as an imposition. Several commented that if the bank insisted then they would have to measure outcomes though there was often an underlying resentment or feeling that Western banks did not understand small businesses, and certainly not ethnic minority businesses.

\section{Women's work}

The role of women in these firms was more complex than that of men. While the two owners quoted above were single, the other two were married and struggled desperately to remain in business while fulfilling family duties. Work-life balance was a key issue ${ }^{30}$ as their roles remained defined in terms of 'wife and mother' rather than as worker or manager. ${ }^{31}$ Business was 'grafted onto well-established female roles' 32 and domestic labour remained a female responsibility. ${ }^{33}$

'It's very important to me to stay here as an entrepreneur ... but then it's also very important to be a good wife, daughter and mother. To do that I have a round of commitments and if I try to avoid them it would be interpreted very badly ... it's like my job is seen as a strange hobby rather than it supporting us in a secure lifestyle.' (Female, IT services)

'In some ways I am lucky as my children always have someone who looks after them 
when I'm not here. But then I get so much parental advice and instructions accompanying this. I have a very good friend with three children who runs her own software firm in London ... there are no relatives so she buys help. This means that she does the paying and she controls what happens.' (Female, law firm)

In the companies with male owners, three were unmarried and under gentle, but continual, pressure to get married. The other three had wives who were not working though they had jobs before their children were born. None of the wives worked in these companies, but all anticipated their wives returning to work or doing something on their own after the children had reached an age where their mothers felt able to leave them. They perceived themselves as having advantages here over non-SEMB friends who were working or running businesses.

While the female owners of companies all had strong family responsibilities to visit relatives, care for relatives and fulfil a particular role, the male owners had few such pressures. This may relate to the different roles assigned to gender or it may be that the size of the sample did not provide an accurate picture. In all ten firms, however, it seemed that the roles of women were still more narrowly defined than those of men. Asian males are found to have a greater degree of support and encouragement from both the family and the community given that they go into business to enjoy a greater degree of independence and to be rewarded for their efforts with the approval of family and community. If strong community ties had not existed their situation would have been more difficult.

Many of the business issues they face are indicative of the business activity they are in, but the cultural issues feature largely. This exploratory research illustrates the need to understand better how relationship marketing can help diverse ethnic minority businesses build upon existing family and community networks.

Female owners had overcome problems and difficulties and were effective in juggling work and family commitments, but were still not perceived as successful except by a few younger members of the family and by non-ethnic community friends and business associates.

\footnotetext{
'There's still this stereotype that Asian women are submissive, are forced to marry early, get beaten up by their husbands ... the pressure to conform, to marry and have children, is enormous, not just from the immediate family but from the wider family and community. There are new opportunities, more women actually finding a route which suits them and which they can do well, than there have been in the past.' (Female, accountancy firm)
}

The relatively low numbers of Asian women involved in running businesses of this type may contribute to this. As numbers rise and this becomes more accepted by the community, these attitudes may change. The main barriers to success are seen by female owners as business related, including expectations of their fulfilling their traditional roles as women in their community and within their families. Stereotypes of Asian women are held both inside and outside the community. They felt exposed to male chauvinism, non-preferential treatment by banks and the perception by others within their communities that they lack knowledge. It had not been easy for them to get start up funds from banks or financial institutions so they had borrowed from community sources and from the family. The weight of advice accompanying the money made this a problematic route to follow. 


\section{CONCLUSIONS}

These owners had key cultural perspectives on running their businesses which both aid and hinder their success. Reliance on the Asian community as a customer base means that the firms gain stability earlier than they might otherwise, though this could mean that mainstream marketing opportunities are missed. Public sector initiatives and programmes were not seen as relevant or useful because they were not perceived as relevant to the SEMBs concerned. Networking, particularly for the female owners, was a key issue. Given a reluctance to network in the Asian business associations, they have less support in developing their companies than their male counterparts. Both male and female owners had little understanding of the potential value of targeting effectively, of marketing consistently or of measuring the outcomes of actions against predicted targets.

Understanding the potential of relationship marketing, and of targeting and measuring are key skills for such SEMBs to hone. There is, however, little evidence of their gaining such skills by themselves or having these skills developed for them by support agencies, especially where owner-managers were still in traditional sectors. In the past, ethnic businesses have been encouraged to 'break out' from ethnic niche businesses like lower-order retailing and catering, but other strategies include using 'ethnic advantage' by exploiting 'cultural' features of a particular community, or 'ethnic enclaves'. The homogeneity attributed to an ethnic enclave ignores, however, the 'harshly competitive environment' in which small ethnic businesses may operate. This may be exacerbated by the way inner city areas are regulated (through planning guidelines) and by the 'external' focus which ignores chronic internal issues such as poor working environments. ${ }^{34} \mathrm{~A}$ clearer focus and commitment to developing business strategies would be of key benefit for such firms.

Given the size of this sample and its exploratory nature, a qualitative approach was adopted. To develop a general model, however, a large-scale quantitative survey will be very useful. The key factors would be to develop the survey in a way that offered a wider view of owners' attitudes to measuring and targeting, and whether with more positive attitudes to these factors, they could become skilled at their marketing implementations and so be more successful. If the design of such a survey allowed respondents to adopt an open and informative approach then these ideas could be properly tested. Despite earlier calls for a more theory-based measure for a 'construct ethnic identification', ${ }^{35}$ this is still lacking. A quantitative approach would bring a more theoretical basis for these ideas to be formed. This would be useful not only for others researching this field, but also for policy makers working to support the small firm sector. There is a gap in the literature covering the actions, growth and establishment of such firms and how to support their successful development.

\section{References}

1 Martin, C., Martin, L. M. and Mabbett, A. (2002) 'SME ownership succession - business support and policy implications', report commissioned for the UK Small Business Service, DTI Small Business Service, Sheffield.

2 Seitz, V. (1998) 'Acculturation and direct purchasing behaviour among ethnic groups in the US: Implications for business practitioners', Journal of Consumer Marketing, Vol. 15, No. 1, pp. 23-31.

3 Korgaonkar, P. K., Karson, E. J. and Lund, D. (2000) 'Hispanics and direct marketing advertising', Journal of Consumer Marketing, Vol. 17, No. 2, pp. 137-157.

4 HMSO (1971) 'Report of the Committee of Inquiry 
on Small Firms' ('Small Firms'), reprinted 1978, HMSO, pp. 23-26.

5 Treacy, M. and Wiersema, F. (1993) 'Customer intimacy and other value disciplines', Harvard Business Review, Vol. 71, No. 1, pp. 84-93.

6 Berry, L. (1995) 'Relationship marketing of services - Growing interest, emerging perspectives', Journal of the Academy of Marketing Science, Vol. 23, No. 4, pp. 236-245.

7 Salway, P. (1993) 'The Oxford Illustrated History of Roman Britain', Oxford University Press, Oxford.

8 Hunt, S. (1994) 'Seven questions for relationship marketing', keynote address at the opening of the MEG Conference, University of Ulster, Coleraine, Northern Ireland.

9 Palmer, A. (1995) 'Relationship marketing: Local implementation of a universal concept', Journal of the Academy of Marketing Science, Vol. 4, No. 4, pp. 471-481.

10 Gronroos, C. (1991) 'The marketing strategy continuum: Towards a marketing concept for the 1990s', Management Decision, Vol. 29, No. 1, pp. 7-13.

11 Harker, M. (1998) 'Relationship marketing defined', presentation to the Academy of Marketing Doctoral Colloquium, Sheffield Metropolitan University, July.

12 Lindgreen, A. and Crawford, I. (1999)

'Implementing, monitoring and measuring a programme of relationship marketing', Qualitative Market Research - An International Journal, Vol. 17, No. 5, pp. 231-239.

13 Christopher, M., Payne, A. and Ballantyne, M. (1991) 'Relationship marketing', Heinemann, London.

14 Barnes, G. (1994) 'Close to the customer: But is it really a relationship?', Journal of Marketing Management, Vol. 10, No. 7, pp. 561-570.

15 Jamal, A. (1998) 'Food consumption among ethnic minorities: The case of British-Pakistanis in Bradford, UK', British Food Journal, Vol. 100, No. 5, pp. 221-227.

16 Ram, M., Abbas, T., Sanghera, B. and Hillin, G. (2000) 'Currying favour with the locals: Balti owners and business enclaves', International Journal of Entrepreneurial Behaviour and Research, Vol. 6, No. 1, pp. $41-55$.

17 Fugita, S. S. and O’Brien, D. (1991) 'Japanese American ethnicity: The persistence of community', University of Washington Press, Seattle.

18 Collins, J. (2002) 'Chinese entrepreneurs: The Chinese diaspora in Australia', International Journal of Entrepreneurial Behaviour and Research, Vol. 8, No. 1, pp. 113-133.

19 Pang, C. L. (2002) 'Business opportunity or food pornography?: Chinese restaurant ventures in Antwerp', International Journal of Entrepreneurial Behaviour and Research, Vol. 8, No. 1, pp. 148-161.

20 Cui, G. and Choudhury, P. (2002) 'Marketplace diversity and cost-effective marketing strategies',
Journal of Consumer Marketing, Vol. 19, No. 1, pp. 54-73.

21 Bristow, D. N. and Asquith, J. A. (1999) 'What's in a name? An intracultural investigation of Hispanic and Anglo consumer preferences and the importance of brand name', Journal of Product and Brand Management, Vol. 8, No. 3, pp. 185-203.

22 Janjuha-Jivraj, S. and Woods, A. (2000) 'Successional issues within Asian family firms: Learning from the Kenyan experience', International Small Business Journal, Vol. 20, No. 1, p. 77.

23 Chan, S. and Janjuha-Jivraj, S. (2000) 'Succession issues in family businesses; blessing or burden?', The 2000 Small Business and Enterprise Development Conference Proceedings, University of Manchester, Manchester, 10th-11th April, pp. 38-48.

24 Martin, L. M. (2001) 'Bending the rules or fudging the paperwork? Documenting learning in SMEs', The Journal of Workplace Learning, Vol. 13, No. 5, pp. 189-197.

25 Social Exclusion Unit (1999) 'Skills for neighbourhood renewal: Local solutions', Final Report of the Policy Action Team on Skills, DfEE, London, December.

26 Goffee, R. (1996) 'Understanding family businesses: Issues for further research', International Journal of Entrepreneurial Behavior and Research, Vol. 2, No. 1, p. 5.

27 Fernandez, M. and Nichols, L. (2002) 'Bridging and bonding capital: Pluralist ethnic relations in Silicon Valley', International Journal of Sociology and Social Policy, Vol. 22, No. 9, pp. 104-122.

28 Reitz, J. G. (1980) 'The survival of ethnic groups', McGraw-Hill, Toronto.

29 Rugimbana, R. and Nwankwo, S. (2003) 'Cross-cultural marketing', Thomson Learning, London, pp. 286-288.

30 Smith, C. (2000) 'Managing work and family in small “copreneurial” business: An Australian study', Women in Management Review, Vol. 15, No. 5/6, pp. 283-289.

31 Marshack, K. J. (1994) 'Copreneurs and dual career couples, are they different?', Entrepreneurship, Theory and Practice, Vol. 19, No. 1, pp. 49-69.

32 Baines, S. and Wheelock, J. (1998) 'Working for each other; Gender, the household and micro business survival and growth', International Small Business Journal, Vol. 17, No. 1, pp. 16-35.

33 Kemmer, D. (1999) 'Food preparation and the division of domestic labour among newly married and cohabiting couples', British Food Journal, Vol. 101, No. 8, pp. 570-579.

34 Social Exclusion Unit (1999) 'Enterprise and social exclusion, national strategy for neighbourhood renewal', Policy Action Team 3, HM Treasury, London, November.

35 Chung, E. and Fisher, E. (2002) 'It's who you know: Intracultural differences in ethnic product consumption', Journal of Consumer Marketing, Vol. 16, No. 5, pp. 482-501. 